\title{
Arousal modulation of memory and amygdala-parahippocampal connectivity: A PET-psychophysiology study in specific phobia
}

\author{
FREDRIK ÅHS, ${ }^{a}$ ÅSA MICHELGÅRD PALMQUIST, ${ }^{\mathrm{b}}$ ANNA PISSIOTA,,${ }^{\mathrm{a}}$ LIEUWE APPEL,${ }^{\mathrm{c}}$ \\ ÖRJAN FRANS, ${ }^{\mathrm{a}}$ ISRAEL LIBERZON, ${ }^{\mathrm{d}}$ TOMAS FURMARK, ${ }^{\mathrm{a}}$ AND MATS FREDRIKSON ${ }^{\mathrm{a}}$ \\ ${ }^{a}$ Department of Psychology, Uppsala University, Uppsala, Sweden \\ ${ }^{\mathrm{b}}$ Department of Neuroscience, Psychiatry, Uppsala University, Uppsala, Sweden \\ ${ }^{\mathrm{c}}$ Uppsala Imanet, GE Healthcare, Uppsala, Sweden \\ ${ }^{\mathrm{d}}$ University of Michigan School of Natural Resources, Department of Psychiatry, Ann Arbor, Michigan, USA
}

\begin{abstract}
Phobic fear is accompanied by intense bodily responses modulated by the amygdala. An amygdala moderated psychophysiological measure related to arousal is electrodermal activity. We evaluated the contributions of electrodermal activity to amygdala-parahippocampal regional cerebral blood flow (rCBF) during phobic memory encoding in subjects with spider or snake phobia. Recognition memory was increased for phobia-related slides and covaried with $\mathrm{rCBF}$ in the amygdala and the parahippocampal gyrus. The covariation between parahippocampal $\mathrm{rCBF}$ and recognition was related to electrodermal activity suggesting that parahippocampal memory processes were associated with sympathetic activity. Electrodermal activity further mediated the amygdala effect on parahippocampal activity. Memory encoding during phobic fear therefore seems contingent on amygdala's influence on arousal and parahippocampal activity.
\end{abstract}

Descriptors: Anxiety, Learning/Memory, fMRI/PET/MRI, Electrodermal, Amygdala, Parahippocampal gyrus

Specific phobia is characterized by excessive and unreasonable fear of objects (e.g., spiders and snakes) that initiates a cascade of behaviors including increased autonomic arousal (Fredrikson, 1981) and avoidance (Hamm, 2009). Phobic stimulation further enhances recognition memory (Muhlberger, Wiedemann, Herrmann, \& Pauli, 2006) whereas memory for nonphobic objects equals that of healthy controls (Airaksinen, Larsson, \& Forsell, 2005). While nonphobic emotional memory enhancement seems due to amygdala's modulation of brain areas in the medial temporal lobe (MTL) memory system (LaBar \& Cabeza, 2006; McGaugh, 2004; Wais, Wixted, Hopkins, \& Squire, 2006; Winters, Saksida and Bussey, 2008), the neural mechanisms of phobic memory are largely unknown.

Emotional stimuli can be characterized along the dimensions of arousal and valence. It has been suggested that arousal, rather than valence, associated with emotional stimulation preferentially enhances memory (Bradley, Greenwald, Petry, \& Lang,

The present study was supported by the Swedish Research Council, the Borgström Foundation, the Swedish Brain Foundation, and the Swedish Council for Working Life and Social Research. We would like to thank the personnel at Uppsala Imanet for excellent research conditions and Clas Linnman for valuable comments on the manuscript.

Address reprint requests to: Address correspondence to: Fredrik Åhs, Department of Psychology, Uppsala University, Box 1225, SE-751 42 Uppsala, Sweden. E-mail: fredrik.ahs@psyk.uu.se
1992). When the encoding material is arousing, the amygdala is engaged in the memory process as shown by correlations between memory and amygdala activity (Cahill et al., 1996; Canli, Zhao, Brewer, Gabrieli, \& Cahill, 2000; Hamann, Ely, Grafton, \& Kilts, 1999). Arousing pictures increase the functional connectivity between the amygdala and the hippocampus and parahippocampal cortex (Kilpatrick \& Cahill, 2003), supporting a modulatory role for the amygdala in emotional memory enhancement (McGaugh, 2004).

Arousal can be indexed by psychophysiological measures of electrodermal activity (Bradley et al., 1992; Lang \& Bradley, 2010). Individual differences in electrodermal activity is correlated to amygdala activity (Cheng, Knight, Smith, \& Helmstetter, 2006; Furmark et al., 1997), and electrical stimulation of the amygdala in subjects undergoing surgery can evoke increased electrodermal activity and emotional experiences (Halgren, Walter, Cherlow, \& Crandall, 1978; Lanteaume et al., 2007). Electrodermal activity further seems to capture individual differences along the arousal dimension (Bradley, Lang, \& Cuthbert, 1993; Lang \& Bradley, 2010).

In studies on arousal enhancement of memory, stimulus characteristics other than arousal, such as visual complexity, could potentially influence memory processes. Therefore, the aim of the present study was to isolate the memory-enhancing effect of emotion by keeping visual content constant between the phobic and nonphobic conditions. This was achieved by selecting 
half of the participants to exhibit phobia for spiders but not snakes, and the other half to exhibit phobia for snakes but not spiders. Because memory for nonphobic material is unaffected in specific phobia (Airaksinen et al., 2005) and since individuals with spider phobia show unbiased memory for snakes (Reinecke, Rinck, \& Becker, 2008), spider and snake phobic individuals can serve as each other's controls. Thus, the nonphobic condition consisted of showing pictures of spiders to subjects with snake phobia and snakes to subjects with spider phobia with the opposite pattern of stimulation during the phobic condition.

Although it seems clear from previous reports that the amygdala modulates MTL memory systems under nonphobicarousing encoding conditions (Kensinger \& Corkin, 2004), this hypothesis has not been tested under phobic states. The present study investigated effects of phobic stimulation on memory and neural activity in the amygdala and the parahippocampal gyrus. Sixteen participants watched phobic and nonphobic pictures while regional cerebral blood flow (rCBF) was measured simultaneously with electrodermal activity. Based on previous research on amygdala involvement in arousal memory (Cahill et al., 1996; Hamann et al., 1999) and autonomic activity (Furmark et al., 1997, Davis, 2006), it was hypothesized that amygdala rCBF would be more strongly correlated to memory performance and electrodermal activity during phobic as compared to nonphobic stimulation. We further predicted that parahippocampal activity would be correlated to recognition memory for phobic pictures due to stronger arousal. This prediction was tested by removing shared variance between electrodermal activity and recognition memory and observing if that would reduce the shared variance between recognition memory and parahippocampal activity. Finally, path analysis was used to test whether electrodermal activity mediated amygdala's influence on parahippocampal activity.

\section{Method}

\section{Subjects}

Sixteen right-handed female volunteers (mean age $=22.8$, $S D=4.1$ ) fulfilling the DSM-IV (American Psychiatric Association, 1994) criteria for either specific spider or snake phobia participated. Diagnosis was determined through a clinical interview. Exclusion criteria were current psychiatric disorder other than specific snake or spider phobia; ever having sought help or undergone treatment for specific phobia, either medical or psychological; ever having been treated for mental disorder; medicating against anxiety; substance abuse; claustrophobia; pregnancy; left-handedness. For a detailed description of the recruitment procedure, see Pissiota et al. (2003). Briefly, subjects were included if they were phobic of one but not the other class of stimuli. Thus, for snake phobic individuals snake pictures induced negative affect and spider pictures acted as nonphobic control stimuli, while the reverse was true for spider phobics. Screening included Swedish versions (Fredrikson, 1983) of the Snake Anxiety Questionnaire (SNAQ, 0-30 points) and the Spider Phobia Questionnaire (SPQ, 0-31 points) (Klorman, Weerts, Hastings, Melamed, \& Lang, 1974). Spider phobic participants had a mean SPQ score of 23.3 and a SNAQ score of 2.4 corresponding to $>95 \%$ and $<25 \%$ percentiles. Snake phobic subjects had scores of 23.9 and 3.2 for the SNAQ and SPQ, respectively, corresponding to $>95 \%$ and $<50 \%$ percentiles.
The SPQ score of subjects phobic of spiders did not differ from the SNAQ score of subjects phobic of snakes $(t(14)=0.63$, $p=.53$ ). The study was approved by the local ethics and radiation safety committees. Written informed consent was obtained from all subjects.

\section{Stimuli and Procedure}

Subjects were presented with pictures of snakes and spiders on a computer screen during scanning. Two sets of pictures for each stimulus category were presented, once with and once without startle probes. Each presentation contained 25 pictures of either snakes or spiders, randomly presented for 2-4 s with an interval of 1-3 s. Thus, subjects saw a total of 50 phobic and 50 nonphobic slides. Subjects were instructed that they would see pictures of spiders or snakes, but were not told that recognition memory would be tested afterwards. Brain imaging was performed on two separate days, with phobic stimuli shown on one day and nonphobic stimuli on the other. The order of conditions was counterbalanced between the subjects. Imaging was performed using PET scans with $\left[{ }^{15} \mathrm{O}\right]$ water. The effect of the startle manipulation has been reported by Pissiota et al. (2003), and the effect of phobic versus nonphobic stimuli on $\mathrm{rCBF}$ was presented in Ahs et al. (2009). In addition, one 60-min [ $\left.{ }^{11} \mathrm{C}\right]$ GR205171 PET scan was performed with symptom provocation on the same days as the $\left[{ }^{15} \mathrm{O}\right]$ water scans in order to measure effects on the substance P Neurokinin-1 receptor system as reported by Michelgard et al. (2007). The $\left[{ }^{11} \mathrm{C}\right] \mathrm{GR} 205171$ PET scans were always conducted after the $\left[{ }^{15} \mathrm{O}\right]$ water scans.

\section{Recognition Memory}

A set-up similar to that used during brain imaging was used during a recognition memory test with pictures being presented on a computer screen while subjects indicated whether they recognized the presented slide or not. Recognition was tested using a forced choice yes/no format. Thirty-six randomly drawn spider and snake pictures of the original 50 shown during the $\mathrm{rCBF}$ assessments were presented together with 12 new spider and snake pictures. Thus, all in all 96 slides were presented during the recognition test (36 old phobic and 36 old nonphobic as well as 12 new phobic and 12 new nonphobic slides). A recognition test was performed on each day of scanning $1.5 \mathrm{~h}$ after scanning was completed. Scans were separated by 7 days. We used signal detection theory to calculate $\mathrm{d}^{\prime}$ (Macmillan \& Creelman, 2005), which served as an unbiased measure of recognition memory for phobic and nonphobic pictures. Memory performance $\left(\mathrm{d}^{\prime}\right)$ was correlated to $\mathrm{rCBF}$ in the amygdala, parahippocampal gyrus, and hippocampus.

\section{Emotional State Measures and Analysis}

After each presentation block, subjects rated the distress experienced during picture presentations on a visual analogue scale $(0=\min , 100=\max )$. Skin conductance was recorded with two $\mathrm{Ag}-\mathrm{AgCl}$ electrodes filled with isotonic electrolytic gel using commercially available equipment (Contact Precision Instruments Inc., London, UK). The signal was high-pass filtered at $0.1 \mathrm{~Hz}$ and analyzed off-line. Electrodermal activity was scored as number of fluctuations larger than $0.05 \mu \mathrm{S}$ per minute using commercial software (Contact Precision Instruments Inc., Lon- 
don, UK). Probability values for pairwise comparison of recognition memory, electrodermal activity, and distress ratings during the phobic and nonphobic condition were calculated using $t$ tests in SPSS 16.0 (SPSS Inc., Chicago, IL).

\section{Image Acquisition and Analysis}

Scans were performed using an ECAT EXACT HR+PET scanner (CTI/Siemens, Knoxville, TN) operated in 3D mode with a 155-mm axial field of view and an axial resolution of approximately $5 \mathrm{~mm}$, producing 63 planes with $2.5-\mathrm{mm}$ plane spacing. Subjects were positioned in the scanner with their head gently fixated. Then, a 10-min transmission scan was performed. Approximately $10 \mathrm{MBq} / \mathrm{kg}$ bodyweight of $\left[{ }^{15} \mathrm{O}\right]$ water was injected during the emission scans and data were collected in three 30-s frames, starting at bolus arrival to the brain. Data were corrected for attenuation and scatter and reconstructed to a $128 \times 128$ matrix using back projection and an $8 \mathrm{~mm}$ Hanning filter. The three 30-s frames for each scan were summed to produce a 90 -s image for each individual and condition to obtain a better statistical reference for realignment and subsequent analyses.

PET images were realigned and normalized to the Montreal Neurological Institute's (MNI) stereotactic template ICBM152, using SPM2 (Wellcome Department of Cognitive Neurology, London, UK). Images were smoothed using a 12-mm Gaussian kernel and scaled to give all scans the same global value. Voxel size was $2 \times 2 \times 2 \mathrm{~mm}$. Data were statistically evaluated using within-group comparisons in SPM2 with $\mathrm{rCBF}$ data fitted to the general linear model (Friston et al., 1994). All co-ordinates (x, y, z) are given in Talairach space (Talairach \& Tournoux, 1988), transformed from MNI space using a nonlinear transformation (http://imaging.mrc-cbu.cam.ac.uk/imaging/MniTalairach).

Bilateral a priori region of interest (ROI) volumes for the amygdala, parahippocampal gyrus, and hippocampus were created in MNI space using the WFU PickAtlas Toolbox (Maldjian, Laurienti, Kraft, \& Burdette, 2003). The parahippocampal gyrus was defined as Brodmann's areas 35 and 36 dilated by $4 \mathrm{~mm}$ to include all circumscribed voxels. The hippocampus proper was also included in this ROI. Statistical images were thresholded at an uncorrected $p$-level of $p<.005$ and an extent threshold of 10 consecutive voxels, which provide an optimal balance between type I and type II errors in cognitive and affective neuroimaging studies (Lieberman and Cunningham, 2009). Criteria for statistical significance for voxels surviving the uncorrected threshold was set to $p<.05$ familywise error-corrected for multiple comparisons within these bilateral ROIs.

Increases to phobic as compared to nonphobic stimuli were analyzed using $t$-contrasts. Voxels within the a priori ROIs that covaried with $\mathrm{d}^{\prime}$ during each condition were identified entering $\mathrm{d}^{\prime}$; as a covariate in the design matrix. The same procedure was used to evaluate the covariation between electrodermal activity in relation to amygdala $\mathrm{rCBF}$. To test whether the influence of parahippocampal activity on $\mathrm{d}^{\prime}$ was statistically dependent on electrodermal activity, $\mathrm{d}^{\prime}$ was orthogonalized (Andrade, Paradis, Rouquette, \& Poline, 1999) to these variables, using a custom Matlab (Mathworks, Inc.) script, before the covariation analysis was run anew. If orthogonalizing $\mathrm{d}^{\prime}$ to electrodermal activity would decrease the parameter estimates for voxels in the parahippocampal gyrus to a statistically nonsignificant level, statistical dependence could be inferred (Baron \& Kenny, 1986). To further test whether memory-related amygdala modulation of the parahippocampal gyrus was mediated by the emotional state, a path analysis was performed using the software Mplus 4.0 (Muthén \& Muthén, 2004). Mplus 4.0 uses bootstrapping methods that can provide more robust tests in small samples such as ours because they do not rely on assumptions of normality (Shrout \& Bolger, 2002). Bootstrapping was performed using 1000 iterations. The fit of each path model was evaluated using $\chi^{2}$ as well as standardized root mean square residual (SRMR). SRMR is the standardized difference between the observed covariance and predicted covariance. A value of zero indicates perfect fit and a value less than .08 is considered good fit. Mean rCBF from the phobic condition was extracted from clusters of voxels in the amygdalae and parahippocampal cortices that showed a positive covariation ( $p<.01$ uncorrected) with recognition memory. One path model was evaluated in each hemisphere. We tested whether electrodermal activity, indexing arousal, mediated the effect of the amygdala on the parahippocampal gyrus by computing the indirect effect via electrodermal activity between these two variables. In this path model, amygdala $\mathrm{rCBF}$ was treated as an exogenous variable with a direct path to electrodermal activity that in turn had a path to $\mathrm{rCBF}$ in the parahippocampal gyrus. Parahippocampal rCBF also had a direct path to $\mathrm{d}^{\prime}$.

\section{Results}

\section{Recognition Memory and Emotional State Measures}

A single subject was classified as outlier ( $\mathrm{d}^{\prime}$ over 3 standard deviations from the mean) for nonphobic stimuli. Subsequently, her data was excluded from analyses that involved $\mathrm{d}^{\prime}$ for the nonphobic condition. Overall, recognition memory as indexed by $\mathrm{d}^{\prime}$ was better for phobic than nonphobic pictures $(t(14)=2.21, p=.04$; Figure 1). The number of nonspecific skin conductance fluctuations (NSF) indexing autonomic arousal, as well as distress ratings, were larger during phobic than nonphobic stimuli (Electrodermal activity: $t(15)=2.98, p=.009$; Distress: $t(15)=11.18, p=1 * 10^{-8}$ ) as has previously been reported in Pissiota et al. (2003).

\section{Amygdala rCBF During Phobic and Nonphobic Stimulus Presentation}

During phobic as compared to nonphobic stimulus presentation, $\mathrm{rCBF}$ increased in the right amygdala (Table 1). Bilateral

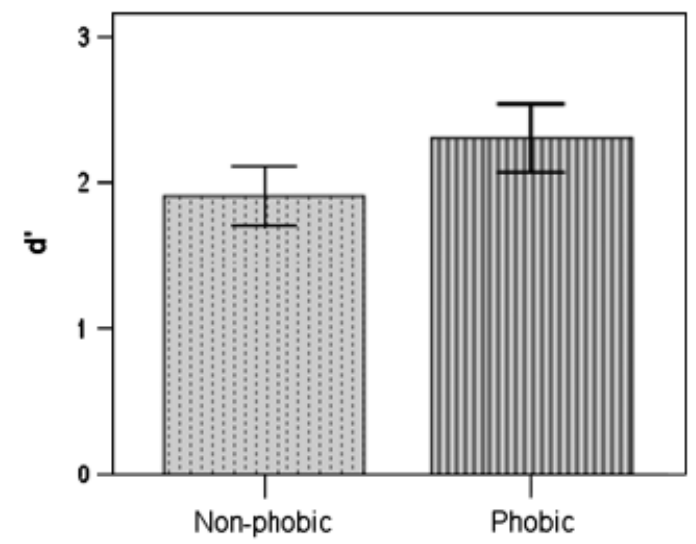

Figure 1. Mean recognition $\left(\mathrm{d}^{\prime}\right)$ following nonphobic and phobic pictures. Error bars represent standard error of the mean. 
Table 1. Increased rCBF During Phobic as Compared to Nonphobic Picture Presentation

\begin{tabular}{lcrr}
\hline \hline Region & Talairach coordinates & $z$ & $p$ corrected \\
\hline Right amygdala & $26,-3,-12$ & 4.08 & .001 \\
Right parahippocampal gyrus & $16,-41,-10$ & 4.53 & .001 \\
Left parahippocampal gyrus & $-28,-45,-10$ & 4.87 & 30 \\
\hline \hline
\end{tabular}

amygdala $\mathrm{rCBF}$ also covaried positively with the index of recognition memory $\left(\mathrm{d}^{\prime}\right)$ during phobic, but not nonphobic, pictures (Table 2). Psychophysiological interaction (PPI) analysis revealed that the difference in magnitude of the covariation between conditions was significant for both amygdalae (Table 2; Figure 2B).

PPI analysis was also used to investigate whether there were stronger couplings between amygdala activity and electrodermal activity during phobic than nonphobic stimuli presentation. Electrodermal activity covaried more strongly with right amygdala activity during phobic than nonphobic stimulus presentation $(\mathrm{x}=28, \mathrm{y}=-8, \mathrm{z}=-13, z=3.28, p=.01$; Figure $2 \mathrm{~A})$.

\section{Parahippocampal rCBF During Phobic and Nonphobic Stimulus Presentation}

During phobic stimulation, $\mathrm{rCBF}$ increased bilaterally in the parahippocampal cortices (Table 1). Recognition memory $\left(\mathrm{d}^{\prime}\right)$ also covaried positively with rCBF bilaterally in parahippocampal cortices (Table 2). Clusters of activated voxels were located in the anteromedial part of the parahippocampal gyrus. During nonphobic stimulation, recognition memory covaried positively with $\mathrm{rCBF}$ in the left parahippocampal gyrus in an area posterior to the cluster of voxels that covaried with memory for phobic pictures (Table 2). PPI analysis indicated that the difference in covariation with recognition memory between phobic and nonphobic pictures was borderline significant in the left, but did not fully reach statistical criterion in the right hemisphere (Table 2; Figure $3 \mathrm{~A}$ and $\mathrm{B}$ ).

\section{Influence of Electrodermal Activity on Amygdala- Parahippocampal Connectivity}

To examine the contribution of arousal and valence to the observed covariation between $\mathrm{d}^{\prime}$ and parahippocampal rCBF during phobic picture presentation, $\mathrm{d}^{\prime}$ was orthogonalized to electrodermal activity. When shared variance with electrodermal activity was partialed out from $\mathrm{d}^{\prime}$, only a few voxels survived the uncorrected threshold of $p<.005$, and no voxels survived at a corrected $p$-level indicating that parahippocampal involvement in memory encoding was related to arousal level (right hemisphere: $\mathrm{x}=14, \mathrm{y}=-31, \mathrm{z}=-7, z=3.31, p=.1,17$ voxels; Figure $3 \mathrm{c}$ and $\mathrm{d}$ ). To test whether arousal was mediating amygdala influences on parahippocampal activity, a path analysis was performed with paths from the amygdala to the parahippocampal gyrus via electrodermal activity. The model tested also included a path between parahippocampal activity and recognition memory (Figure 4). Electrodermal activity mediated the effect of amygdala rCBF on parahippocampal $\mathrm{rCBF}$ in both hemispheres (Right: $A B=0.26, S E=0.14, p=.05$, Figure 4a; Left: $A B=0.24, S E=0.10, p=.02$, Figure $4 \mathrm{~b})$. Both models showed adequate fit (Right: $\chi^{2}(3)=5.88, p=.12, \mathrm{SRMR}=0.10$; Left: $\chi^{2}(3)=4.57, p=.21$, SRMR $\left.=0.077\right)$.

\section{Discussion}

The present study investigated the neural correlates of memory for phobic stimuli. Using $\left[{ }^{15} \mathrm{O}\right]$ water PET with simultaneous recordings of electrodermal activity, we investigated the contribution of this arousal-related psychophysiological measure to amygdala and parahippocampal activity at the time of encoding. The emotional effect on memory was isolated by keeping visual inputs constant between phobic and nonphobic conditions. Results can be summarized in 4 main findings: (1) During encoding, phobic stimulation enhanced the correlation between amygdala and electrodermal activity; (2) Amygdala and parahippocampal activity predicted subsequent recognition of phobic pictures; (3) Parahippocampal activity no longer predicted recognition memory when the variance shared with electrodermal activity was partialed out; (4) Path-analysis confirmed that arousal mediated the effect of amygdala activity on parahippocampal activity. Collectively, results suggest that amygdalae-related arousal

Table 2. Covariation Between Recognition Memory $\left(d^{\prime}\right)$ and $r C B F$ in the MTL During Phobic and Nonphobic Picture Presentation

\begin{tabular}{|c|c|c|c|c|}
\hline & Talairach coordinates & $z$ & $p$ corrected & Voxels \\
\hline \multicolumn{5}{|l|}{ Nonphobic pictures } \\
\hline Left parahippocampal gyrus & $-48,-34,-20$ & 3.55 & .049 & 49 \\
\hline \multicolumn{5}{|l|}{ Phobic pictures } \\
\hline Left amygdala & $-18,-5,-22$ & 3.16 & .016 & 10 \\
\hline Right amygdala & $24, \quad-6,-11$ & 4.00 & .005 & 104 \\
\hline Left parahippocampal gyrus & $-28,-15,-21$ & 3.96 & .013 & 322 \\
\hline Right parahippocampal gyrus & $14,-31,-7$ & 4.02 & .01 & 115 \\
\hline \multicolumn{5}{|l|}{ Phobic $>$ Nonphobic pictures } \\
\hline Left amygdala & $-16,-8,-11$ & 3.02 & .022 & 14 \\
\hline Right amygdala & $18,-6,-13$ & 3.70 & .003 & 59 \\
\hline Left parahippocampal gyrus & $-14,-5,-23$ & 3.47 & .053 & 49 \\
\hline Right parahippocampal gyrus & $14,-2,-29$ & 3.18 & .12 & 30 \\
\hline
\end{tabular}


NSF

Phobic $>$ Non-phobic

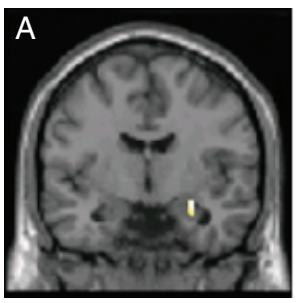

d'

Phobic $>$ Non-phobic

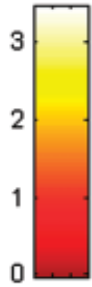

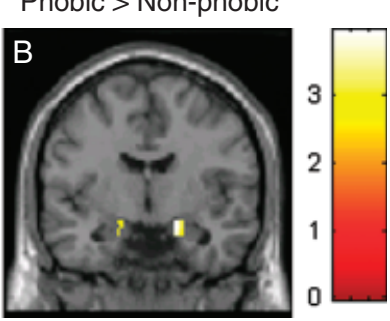

Figure 2. Coronal images showing (A) increase in intersubject covariations between amygdala $\mathrm{rCBF}$ and nonspecific fluctuations in electrodermal activity; (B) increase in intersubject covariations between amygdala $\mathrm{rCBF}$ and recognition memory $\left(\mathrm{d}^{\prime}\right)$ during phobic as compared to nonphobic pictures. Statistical maps overlaid on an MR image shown at $\mathrm{y}=-6$ and thresholded at $p<.005$, uncorrected. The color bars represent $t$-values. Only voxels surviving this threshold within the amygdala are shown.

influence parahippocampal memory processes in phobic fear.

Individual differences in electrodermal activity were associated with amygdala activity during encoding of phobic stimuli. This suggests that amygdala processing of phobic stimuli is associated with sympathetic activity associated with arousal. The amygdala might therefore be involved in the production of bodily arousal responses, possibly through interaction with brainstem areas such as the locus coeruleus (Sterpenich et al., 2006). Amygdala activity was further correlated to memory for phobic material. These results link memory and arousal to amygdala activity. A previous study found that electrodermal activity at encoding was positively associated with memory for emotional material (Buchanan, Etzel, Adolphs, \& Tranel, 2006). Thus, bodily arousal seems to be associated with facilitation of memory. The correlative evidence is supported by a lesion study in

humans (Ahs, Frans, Tibblin, Kumlien, \& Fredrikson, 2010). In that study, controls showed a linear increase in memory performance with increasing stimulus arousal. Patients with resections to the anterior medial temporal lobe, on the other hand, did not show arousal enhanced memory. These data suggest that anteromedial temporal lobe structures, such as the amygdala, are necessary for emotional memory enhancement. Taken together with the current findings, it seems that amygdala activation predicts individual differences in arousal level as well as memory, and that memory facilitation is related to sympathetic activation.

While previous studies have varied extrinsic stimulus arousal to study effects on amygdala activity memory, a recent study has directly manipulated the intrinsic arousal state of the participants. The arousal state, as indexed by electrodermal activity, can be decreased by inhalation of the anesthetic gas sevoflurane (Ledowski, Paech, Storm, Jones, \& Schug, 2006). Alkire et al. (2008) studied the effect of sevoflurane on emotional memory and amygdala-hippocampal connectivity. They found a dosedependent relationship between sevoflurane concentration and memory for arousing material. This relation was associated with decreased functional coupling between the amygdala and the hippocampus and suggests that altering intrinsic arousal has similar effects on amygdala processing of emotional stimuli as extrinsically driven processes. These amygdala processes, in turn, seem to have effects on hippocampal memory function.

Parahippocampal activity at the time of encoding predicted phobic memory in the present study. The variance in phobic memory that could be explained by parahippocampal activity was related to electrodermal activity. These results suggest that arousal level modulates activity in the parahippocampal gyrus and enhance the probability for stimuli to be remembered. The hypothesis that arousal would mediate the effect of amygdala activity on parahippocampal activity was further strengthened by a path analysis. While previous results have shown a functional
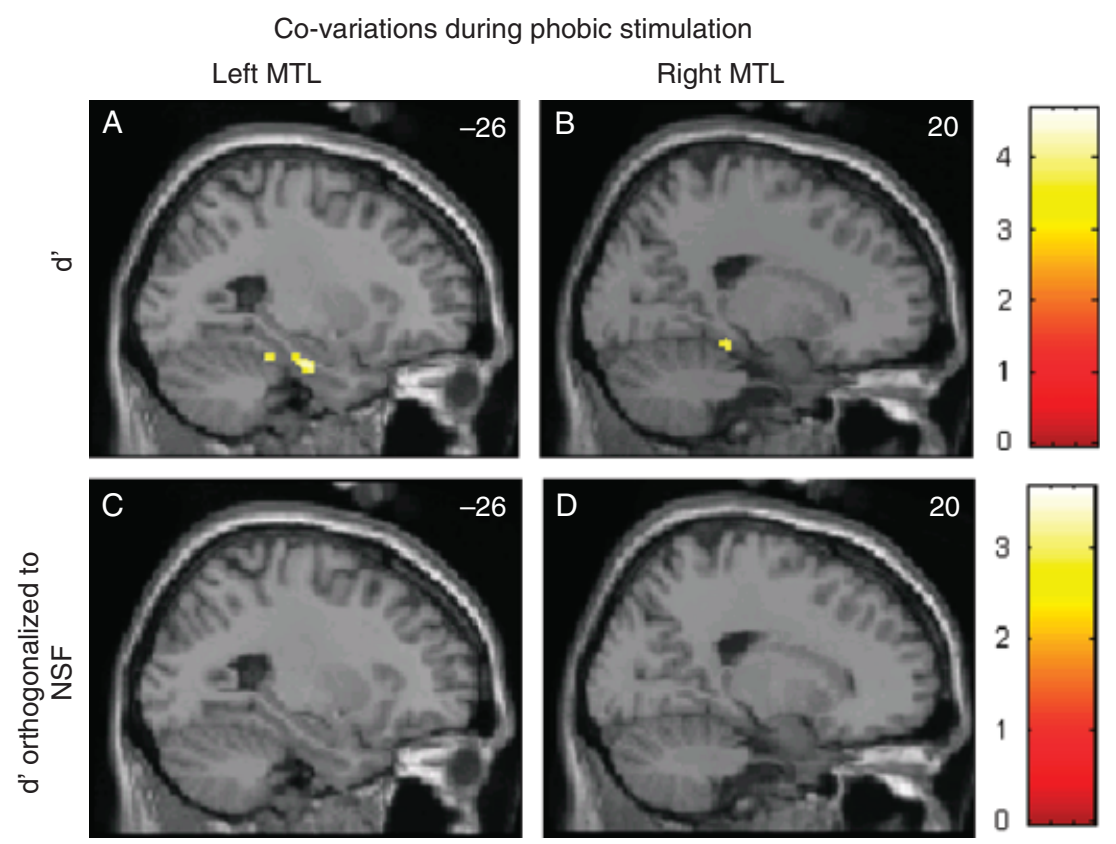

Figure 3. Covariation between recognition memory $\left(\mathrm{d}^{\prime}\right)$ and parahippocampal $\mathrm{rCBF}$ during phobic stimuli presentation in (A) the left, and (B) the right parahippocampal gyrus. Covariation when $\mathrm{d}^{\prime}$ was orthogonalized to electrodermal activity in (C) the left, and (D) the right parahippocampal gyrus. Colorbars represent $t$-values. Statistical maps overlaid on an MR image thresholded at $p<.005$, uncorrected. Only voxels surviving this threshold within the parahippocampal gyrus and hippocampus are shown. 
A

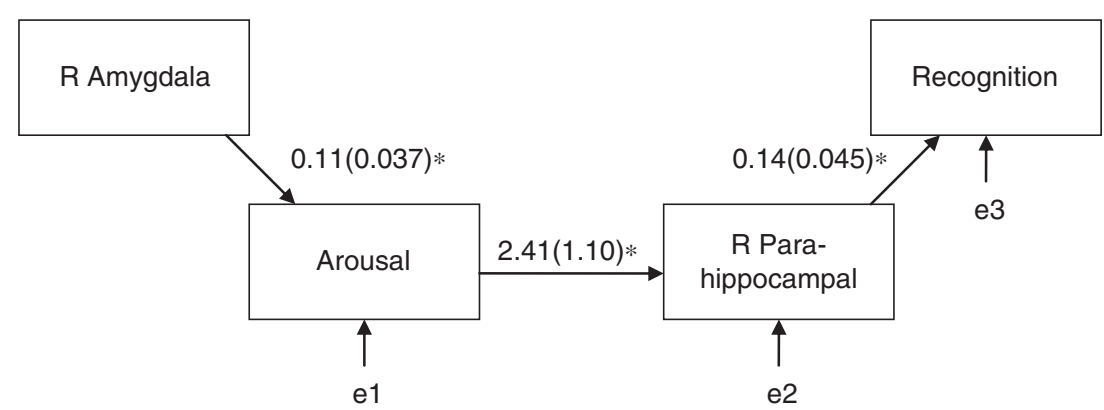

B

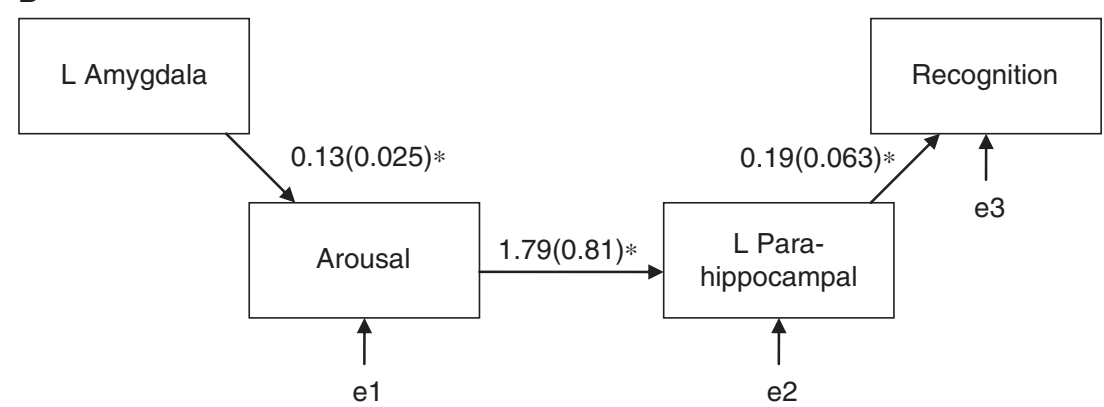

Figure 4. Path model testing if amygdala effects on parahippocampal rCBF during phobic picture presentation are mediated by arousal as indexed by electrodermal activity. Arrows are labeled with unstandardized path coefficients and standard errors in parenthesis. Residuals of endogenous variables are illustrated by e1, e2, and e3. (A) Indirect effects of amygdala on parahippocampal gyrus mediated by electrodermal activity indexing arousal reached borderline significance in the right hemisphere $(A B=0.26, S E=0.14, p=.05)$. (B) Indirect effects of amygdala on parahippocampal gyrus mediated by arousal were significant in the left hemisphere $(A B=0.24, S E=0.10, p=.02) . \mathrm{L}=$ left; $\mathrm{R}=$ right; $* p<0.05$.

coupling between amygdala activity and parahippocampal/hippocampal activity during encoding of emotional pictures (Dolcos, LaBar, \& Cabeza, 2004; Richardson, Strange, \& Dolan, 2004), the present results suggest that this coupling is related to arousal. This proposition is consistent also with a number of studies indicating that the amygdala responds to biologically salient stimuli regardless of hedonic tone (c.f. Fusar-Poli et al. 2009).

Recognition memory for nonphobic pictures was correlated to activity in the parahippocampal gyrus but, notably, not to amygdala activity. This is in accordance with previous studies in monkeys and humans that have mapped recognition memory to the parahippocampal gyrus (Richardson et al., 2004; ZolaMorgan, Squire, Amaral, \& Suzuki, 1989). The maximum covariation between rCBF during encoding and memory performance during neutral cues was observed in an area posterior to the maximum correlation during the highly arousing condition, a response pattern previously observed to segregate emotional from nonemotional memory encoding (Dolcos et al., 2004).

A limitation of the present study is that results might not generalize to subjects without animal phobia. However, memory function does not seem to be altered in animal phobia (Wais et al., 2006). Also, the pattern of activation seems to overlap well with previous studies on emotional memory conducted in nonphobic individuals (Bradley et al., 1992). Therefore, results could reflect memory processes under intense distress that might be present during traumatic events also in nonphobic subjects.

In conclusion, we found that amygdala activity predicted phobic memory. This finding parallels previous reports on nonphobic arousal enhancement of memory and might imply quantitative rather than qualitative differences between memory for mildly and intensely arousing emotions. Further, a memoryrelated influence of the amygdala on the parahippocampal gyrus was mediated by physiological arousal during encoding of phobic, but not nonphobic, stimuli. The results contribute to the understanding of how arousal interacts with memory systems and imply that arousal is related to amygdala-parahippocampal connectivity. This suggests that the association between amygdala activity and phobic memory operates through arousal mediated amygdala-hippocampal connectivity.

\section{References}

Ahs, F., Frans, O., Tibblin, B., Kumlien, E., \& Fredrikson, M. (2010). The effects of medial temporal lobe resections on verbal threat and fear conditioning. Biological Psychology, 83, 41-46.

Ahs, F., Pissiota, A., Michelgard, A., Frans, O., Furmark, T., Appel, L., \& Fredrikson, M. (2009). Disentangling the web of fear: Amygdala reactivity and functional connectivity in spider and snake phobia. Psychiatry Research-Neuroimaging, 172, 103108.
Airaksinen, E., Larsson, M., \& Forsell, Y. (2005). Neuropsychological functions in anxiety disorders in population-based samples: Evidence of episodic memory dysfunction. Journal of Psychiatric Research, 39, 207-214.

Alkire, M. T., Gruver, R., Miller, J., McReynolds, J. R., Hahn, E. L., \& Cahill, L. (2008). Neuroimaging analysis of an anesthetic gas that blocks human emotional memory. Proceedings of the National Academy of Sciences of the United States of America, 105, 1722-1727. 
American Psychiatric Association (1994). Diagnostic and statistical manual of mental disorders (4th ed.). Washington, DC: American Psychiatric Association.

Andrade, A., Paradis, A. L., Rouquette, S., \& Poline, J. B. (1999). Ambiguous results in functional neuroimaging data analysis due to covariate correlation. NeuroImage, 10, 483-486.

Baron, R. M., \& Kenny, D. A. (1986). The moderator mediator variable distinction in social psychological-research: Conceptual, strategic, and statistical considerations. Journal of Personality and Social Psychology, 51, 1173-1182.

Bradley, M. M., Greenwald, M. K., Petry, M. C., \& Lang, P. J. (1992). Remembering pictures: Pleasure and arousal in memory. Journal of Experimental Psychology-Learning Memory and Cognition, 18, 379390.

Bradley, M. M., Lang, P. J., \& Cuthbert, B. N. (1993). Emotion, novelty, and the startle reflex: Habituation in humans. Behavioral Neuroscience, 107, 970-980.

Buchanan, T. W., Etzel, J. A., Adolphs, R., \& Tranel, D. (2006). The influence of autonomic arousal and semantic relatedness on memory for emotional words. International Journal of Psychophysiology, 61, 26-33.

Cahill, L., Haier, R. J., Fallon, J., Alkire, M. T., Tang, C., Keator, D., . . . McGaugh, J. L. (1996). Amygdala activity at encoding correlated with long-term, free recall of emotional information. Proceedings of the National Academy of Sciences of the United States of America, 93, 8016-8021.

Canli, T., Zhao, Z., Brewer, J., Gabrieli, J. D. E., \& Cahill, L. (2000). Event-related activation in the human amygdala associates with later memory for individual emotional experience. Journal of Neuroscience, 20, RC99.

Cheng, D. T., Knight, D. C., Smith, C. N., \& Helmstetter, F. J. (2006). Human amygdala activity during the expression of fear responses. Behavioral Neuroscience, 120, 1187-1195.

Davis, M. (2006). Neural systems involved in fear and anxiety measured with fear-potentiated startle. American Psychologist, 61, 741-756.

Dolcos, F., LaBar, K. S., \& Cabeza, R. (2004). Dissociable effects of arousal and valence on prefrontal activity indexing emotional evaluation and subsequent memory: An event-related fMRI study. NeuroImage, 23, 64-74.

Fredrikson, M. (1981). Orienting and defensive reactions to phobic and conditioned fear stimuli in phobics and normals. Psychophysiology, $18,456-465$.

Fredrikson, M. (1983). Reliability and validity of some specific fear questionnaires. Scandinavian Journal of Psychology, 24, 331-334.

Friston, K. J., Holmes, A. P., Worsley, K. J., Poline, J. B., Frith, C. D., \& Frackowiak, R. S. J. (1994). Statistical parametric maps in functional imaging: A general linear approach. Human Brain Mapping, 2, 189210

Fischer, H, Wik, G, Larsson, M, \& Fredrikson, M (1997). The amygdala and individual differences in fear conditioning. Neuro Report, 8, 39573960 .

Fusar-Poli, P., Placentino, A., Carletti, F., Landi, P., Allen, P., Surguladze, S., ... Politi, P. (2009). Functional atlas of emotional faces processing: A voxel-based meta-analysis of 105 functional magnetic resonance imaging studies. Journal of Psychiatry and Neuroscience, $34,418-432$.

Halgren, E., Walter, R. D., Cherlow, D. G., \& Crandall, P. H. (1978). Mental phenomena evoked by electrical-stimulation of human hippocampal formation and amygdala. Brain, 101, 83-117.

Hamann, S. B., Ely, T. D., Grafton, S. T., \& Kilts, C. D. (1999). Amygdala activity related to enhanced memory for pleasant and aversive stimuli. Nature Neuroscience, 2, 289-293.

Hamm, A. O. (2009). Specific phobias. Psychiatric Clinics of North America, 32, 577-591.

Hamm, A. O., \& Weike, A. I. (2005). The neuropsychology of fear learning and fear regulation. International Journal of Psychophysiology, 57, 5-14.

Kensinger, E. A., \& Corkin, S. (2004). Two routes to emotional memory: Distinct neural processes for valence and arousal. Proceedings of the National Academy of Sciences of the United States of America, 101, 3310-3315.

Kilpatrick, L., \& Cahill, L. (2003). Amygdala modulation of parahippocampal and frontal regions during emotionally influenced memory storage. NeuroImage, 20, 2091-2099.
Klorman, R., Weerts, T. C., Hastings, J. E., Melamed, B. G., \& Lang, P. J. (1974). Psychometric description of some specific-fear questionnaires. Behavior Therapy, 5, 401-409.

LaBar, K. S., \& Cabeza, R. (2006). Cognitive neuroscience of emotional memory. Nature Reviews Neuroscience, 7, 54-64.

Lang, P. J., \& Bradley, M. M. (2010). Emotion and the motivational brain. Biological Psychology, 84, 437-450.

Lanteaume, L., Khalfa, S., Regis, J., Marquis, P., Chauvel, P., \& Bartolomei, F. (2007). Emotion induction after direct intracerebral stimulations of human amygdala. Cerebral Cortex, 17, 1307-1313.

Ledowski, T., Paech, M. J., Storm, H., Jones, R., \& Schug, S. A. (2006). Skin conductance monitoring compared with bispectral index (R) monitoring to assess emergence from general anaesthesia using sevoflurane and remifentanil. British Journal of Anaesthesia, 97, 187-191.

Lieberman, M. D., \& Cunningham, W. A. (2009). Type I and Type II error concerns in fMRI research: Re-balancing the scale. Social Cognitive and Affective Neuroscience, 4, 423-428.

Macmillan, N. A., \& Creelman, C. D. (2005). Detection theory: A user's guide ((2nd ed)). Mahwah, NJ: Lawrence Erlbaum Associates Inc.

Maldjian, J. A., Laurienti, P. J., Kraft, R. A., \& Burdette, J. H. (2003). An automated method for neuroanatomic and cytoarchitectonic atlas-based interrogation of fMRI data sets. NeuroImage, 19, 12331239.

McGaugh, J. L. (2004). The amygdala modulates the consolidation of memories of emotionally arousing experiences. Annual Review of Neuroscience, 27, 1-28.

Michelgard, A., Appel, L., Pissiota, A., Frans, O., Langstrom, B., Bergstrom, M., \& Fredrikson, M. (2007). Symptom provocation in specific phobia affects the substance $P$ neurokinin-1 receptor system. Biological Psychiatry, 61, 1002-1006.

Muhlberger, A., Wiedemann, G., Herrmann, M. J., \& Pauli, P. (2006). Phylo- and ontogenetic fears and the expectation of danger: Differences between spider- and flight-phobic subjects in cognitive and physiological responses to disorder-specific stimuli. Journal of $A b$ normal Psychology, 115, 580-589.

Muthén, L. K., \& Muthén, B. O. (2004). Mplus user's guide (4th ed.). Los Angeles, CA: Muthén \& Muthén.

Pissiota, A., Frans, O., Michelgard, A., Appel, L., Langstrom, B., Flaten, M. A., \& Fredrickson, M. (2003). Amygdala and anterior cingulate cortex activation during affective startle modulation: A PET study of fear. European Journal of Neuroscience, 18, 1325-1331.

Reinecke, A., Rinck, M., \& Becker, E. S. (2008). How preferential is the preferential encoding of threatening stimuli? Working memory biases in specific anxiety and the attentional blink. Journal of Anxiety Disorders, 22, 655-670.

Richardson, M. P., Strange, B. A., \& Dolan, R. J. (2004). Encoding of emotional memories depends on amygdala and hippocampus and their interactions. Nature Neuroscience, 7, 278-285.

Shrout, P. E., \& Bolger, N. (2002). Mediation in experimental and nonexperimental studies: New procedures and recommendations. Psychological Methods, 7, 422-445.

Sterpenich, V., D'Argembeau, A., Desseilles, M., Balteau, E., Albouy, G., Vandewalle, G., ... Maquet, P. (2006). The locus ceruleus is involved in the successful retrieval of emotional memories in humans. Journal of Neuroscience, 26, 7416-7423.

Talairach, J., \& Tournoux, P. (1988). Co-planar stereotactic atlas of the human brain. Stuttgart, Germany: Georg Thieme Verlag.

Wais, P. E., Wixted, J. T., Hopkins, R. O., \& Squire, L. R. (2006). The hippocampus supports both the recollection and the familiarity components of recognition memory. Neuron, 49, 459-466.

Winters, B. D., Saksida, L. M., \& Bussey, T. J. (2008). Object recognition memory: Neurobiological mechanisms of encoding, consolidation and retrieval. Neuroscience and Biobehavioral Reviews, 32, 1055-1070.

Zola-Morgan, S., Squire, L. R., Amaral, D. G., \& Suzuki, W. A. (1989). Lesions of perirhinal and parahippocampal gyrus that spare the amygdala and hippocampal formation produce severe memory impairment. Journal of Neuroscience, 9, 4355-4370.

(Received October 28, 2010; ACCePted May 24, 2011) 